\title{
Endogamy and genetic variability in selective mating using distribution of extremes $^{1}$
}

\author{
Marcelo Jangarelli², Ricardo Frederico Euclydes ${ }^{3}$
}

\footnotetext{
${ }^{1}$ Financed by FAPERJ.

2 Departamento de Matemática (Área de Estatística) - UFRRJ, Seropédica, RJ, Brasil.

${ }^{3}$ Departamento de Zootecnia - UFV, Viçosa, MG, Brasil.
}

ABSTRACT - The objective of this study was to evaluate selective mating using distribution of extremes, among other mating strategies, on its ability to decrease the endogamy and the loss of genetic variability. The genetic simulation system (Genesys) was used to simulate two genomes (each one with a single characteristic whose distinction was the value of heritability) and the base and original populations. Each initial population was submitted to assisted selection by markers for ten consecutive generations. For evaluation of strategies, the estimated parameters were phenotypic value, endogamy and additive genetic variance, in different family sizes, for both characteristics. In all scenarios combining heritability and family sizes, the selective mating was superior to the others, in the ability to decrease endogamy and maintain higher magnitudes of genetic variability. Consequently, superior phenotypic increments were obtained, pointing to a major detection of quantitative trait loci in the assisted selection by markers due to gradual decrease of the additive genetic variance over the generations.

Key Words: additive genetic variance, selection assisted by markers, selective genotyping, simulation

\section{Introduction}

Mating strategies allow rational use of genetically superior animals in breeding programs (Carneiro et al., 2007). According to Neves et al. (2009), this scenario depicts direct mating, which can be done by the combination of similar or not similar animals, using the phenotype or genotype of the animals as criteria.

Selective mating, following the methodology of selective genotyping using the distribution of extremes, is a strategy to increase the capacity of detection of quantitative trait loci (Jin et al., 2004; Ruy et al., 2005; Rosa, 2007). In selective mating, individuals present in the upper and lower extremes of a normal distribution of genetic or phenotypic parameter assessed in the experimental population were used (Bovenhuis \& Spelman, 2000).

The progress seen in breeding programs corroborates the increase of endogamy due to the spread of a few individuals of superior genetic material (Breda et al., 2004; Reis et al., 2009). The reduction in the genetic variability is a major consequence of inbreeding. Usually quantified by the additive genetic variance, the decrease of genetic variability in the population minimizes the ability to promote selection and, consequently, the genetic gain that could be achieved in breeding programs (Moreira et al., 2007; Malhado et al., 2009; Reis et al., 2009; Jacometo et al., 2010). The indiscriminate use of selection methods aiming to increase the phenotypic value, without a thorough evaluation of genetic relevant parameters to the improvement, may influence the performance to be achieved in programs.

The objective of this study was to evaluate the selective mating using the distribution of extremes, among other mating strategies, in the ability to decrease the endogamy and the loss of genetic variability, as well as to optimize the value of the phenotypic trait in marker-assisted selection.

\section{Material and Methods}

Data simulated by the Genesys genetic simulation program (Genetic System, version 2009) (Euclydes, 2009) were used. This system, written in the FORTRAN programming language, allows the simulation of complex genomes, enabling the study of genetic populations following assumptions and statistics of interest. The simulation has contributed to the advancement of genomics and other areas of genetic improvement. It can be used at any stage of a breeding program, to evaluate, prove or refute new methodologies and techniques.

Two hypothetical genomes, whose distinction was in the value of the heritability of the characteristic, were simulated, separately. Each genome was composed of a single quantitative trait with heritability of 0.10 and 0.40 . 
Each proposed genome was characterized genetically: they were 958 centiMorgan (cM) long; the molecular markers were strategically placed at every five cM, totaling 191 markers; 200 quantitative loci (QTL) associated with the characteristic, distributed along 40 chromosomes of random size; the additive effects of QTL were simulated following the normal distribution of phenotypic data; quantitative loci were diallel and did not have a diversion of dominance or epistasis; environmental effects were simulated according to the normal distribution; the simulated phenotypic data showed an average of 10.00 units and standard deviation of 2.00 units.

For each simulated genomic structure a base population was built consisting of 500 males and 500 females $(1,000$ individuals), unrelated to each other. With the 1,000 descendents randomly selected from each base population, obtained by crossing 100 males and 100 females (one female/male), producing 10 descendent/female/male (1,000 individuals), the initial populations were formed. Each initial population was subjected to marker-assisted selection for 10 consecutive generations with 20 replications, in order to minimize the effects of genetic fluctuations. The use of molecular markers in breeding programs, implemented by marker-assisted selection, can benefit the selection processes when characteristics of low and medium heritability are admitted, where the environment has considerable involvement in phenotypic expression (Rodrigues et al., 2010; Sousa et al., 2011). The selection was conducted in order to increase the phenotypic value.

From each initial population, breeders were selected based on their genotypes, according to the number of identified molecular markers that were associated with quantitative loci. This way, the genitors elected in each generation represented individuals with greater number of markers statistically associated to QTL. In each generation, the ten males and ten females (one female/male) which obtained the best performances were mated. The number of progenies in each cross was dependent on family size: 10 , 20, 30, 40 and 50, which corresponded to 10, 20, 30, 40 and 50 descendants in ten matings (one female/male), respectively. These descendants formed the following generation.

In marker-assisted selection, three mating strategies were compared in five mentioned family sizes. The selective mating between the genitors was evaluated, following the principle of selective genotyping (distribution of extremes). In this strategy, males and females selected were ordered separately, based on the number of markers associated with quantitative loci. Mating was conducted between individuals placed at opposite extremes. The mating was carried out with males with the best performance with regard to identification of markers linked to QTL, referred to as the best (located at the upper end of their classification) and the females with the worst performances in identifying markers, referred as the worst (located at the lower end of their classification), and vice versa (worst male versus best female). Two other strategies were compared. In the first, among the individuals selected, males and females with the best performance in identifying markers were mated, and also, males and females with lower performance in the detection of markers associated with QTL, referred to as the worst. In the second strategy the selected breeders were randomly mated.

The number of selected genitors ( 20 - ten males and ten females) was maintained over the generations under markerassisted selection. Thus, the initial population obtained for each genome (by level of heritability of the trait) and the three mating strategies were combined with the five mentioned family sizes, totaling fifteen strategies, i.e., each mating was evaluated in five considered sizes. The markerassisted selection was realized in each strategy, separately, which resulted in 15 selections, all starting from the same phenotypic value (10 units).

The genetic simulation algorithm method Genesys uses the brand simple method to identify associations between markers and quantitative loci in the selection assisted by molecular markers. This method verifies the association between each marker and the trait of interest, by means of linear regression analysis between marker genotypes and phenotypic values of the descendents of matings. The significance level of 0.05 in the simple linear regression was adopted.

The analysis of association between markers and quantitative loci can be estimated by the regression of the values of quantitative trait depending on the genotype of the marker. In this case, it is necessary to code the three genotypes of the marker ( $\mathrm{MM}, \mathrm{Mm}$ and $\mathrm{mm}$ ) to perform the regression analysis. In general, the codes used are 1,0 and -1 for additive effect and 0, 1 and 0 for an effect attributed to the dominance, or 2, 1 and 0 for a general effect (when considering only the additive effect), for genotypes MM, Mm and mm, respectively (Schuster \& Cruz, 2008).

In this study, the deviations of dominance were disregarded, as reported in the genetic characterization of the simulated genomes. Therefore, to perform the simple linear regression in the population, the following additive model was used:

$Y_{j}=\beta_{0}+\beta_{1} X_{j}+\varepsilon_{j}$,

where: $Y_{j}=$ phenotypic value of quantitative trait evaluated in the $\mathrm{j}$-th individual of the population; $\mathrm{X}_{\mathrm{j}}=$ marker code 
$(M M=2, M m=1$ and $m m=0) ; \beta_{0}=$ intercept of the regression (average feature); $\beta_{1}=$ inclination of the straight line for additive effect; $\varepsilon_{\mathrm{j}}=$ random error manifested in the characteristic in the $\mathrm{j}$-th individual.

This way, in the evaluation of 100, 200, 300, 400 and 500 individuals in each generation, for 10, 20, 30, 40 and 50 family sizes, respectively, the following data were found (Table 1):

The matrices used in the model $Y_{j}=\beta_{0}+\beta_{1} X_{j}+\varepsilon_{j}$ are described below:

$$
\mathrm{Y}=\left[\begin{array}{l}
y_{11} \\
y_{21} \\
\ldots \\
y_{n 1,1} \\
y_{12} \\
y_{22} \\
\ldots \\
y_{n 2,2} \\
y_{13} \\
y_{23} \\
\ldots \\
y_{n 3,3}
\end{array}\right]_{1} \mathrm{X}=\left[\begin{array}{cc}
1 & 2 \\
1 & 2 \\
\ldots & \ldots \\
1 & 1 \\
1 & 1 \\
\ldots & \ldots \\
1 & 0 \\
1 & 0
\end{array}\right]_{2} \quad \beta=\left[\begin{array}{l}
\beta_{11} \\
\beta_{1}
\end{array}\right]_{1} \mathrm{e} \varepsilon=\left[\begin{array}{l}
e_{21} \\
\ldots \\
e_{12} \\
e_{22} \\
\ldots \\
e_{n 3,3}
\end{array}\right]_{1}
$$

To compare the mating strategies adopted in markerassisted selection the average of phenotypic values, the coefficients of endogamy and additive genetic variance, in each generation were estimated. Comparisons between the estimated parameters were performed at each level of heritability, according to family size.

Table 1 - Coding assigned to the marker according to its genotype

\begin{tabular}{lccc}
\hline Genotype & Number of individuals & Characteristic values & $\mathrm{X}$ code \\
\hline $\mathrm{MM}$ & $\mathrm{n}_{1}$ & $\mathrm{y}_{11}, \mathrm{y}_{21}, \ldots \mathrm{y}_{\mathrm{n} 1,1}$ & 2 \\
$\mathrm{Mm}$ & $\mathrm{n}_{2}$ & $\mathrm{y}_{12}, \mathrm{y}_{22}, \ldots \mathrm{y}_{\mathrm{n} 2,2}$ & 1 \\
$\mathrm{~mm}$ & $\mathrm{n}_{3}$ & $\mathrm{y}_{13}, \mathrm{y}_{23}, \ldots \mathrm{y}_{\mathrm{n} 3,3}$ & 0 \\
\hline
\end{tabular}

\section{Results and Discussion}

In initial generations, similarity was observed in phenotypic values between mating strategies for the trait of low heritability $\left(\mathrm{h}^{2}=0.10\right)$, in all family sizes (Table 2 ). However, from the 5th/6th generation, especially for larger families (30, 40 and 50), superior phenotype growth was observed by adopting the selective mating among the best and the worst genitors selected (distribution of extremes). Among the random mating strategies and among the best relative phenotypic similarity in progress is noted, despite the slight advantage in mating among the best in families with 10, 40 and 50 descendents (Table 2).

As the capacity of QTL detection is related to the number of individuals and their genotypic divergence, the genetic variability favored in matings involving contrasting individuals contributes to improvement in breeding programs (Bhering \& Cruz, 2008). This way, according to Bovenhuis and Spelman (2000), Ruy et al. (2005) and Rosa (2007), it is acceptable that the application of the distribution of extremes in selective mating brings better results for the characteristic on which individuals were selected. Individuals of one part of the progeny contribute more to the information of marker linking and QTL than others. The genetically divergent individuals are the most informative for QTL detection. Those whose genotype can be inferred from the phenotype, i.e., their genotypes have the most favorable or unfavorable alleles for the trait, appear in this scenario of greater genetic diversity (heterozygosity). In the normal distribution for a given quantitative character, the progenies with phenotypic values of more than one standard deviation represent approximately 33\% of the

Table 2 - Phenotypic averages values and standard deviations for 0.10 heritability trait

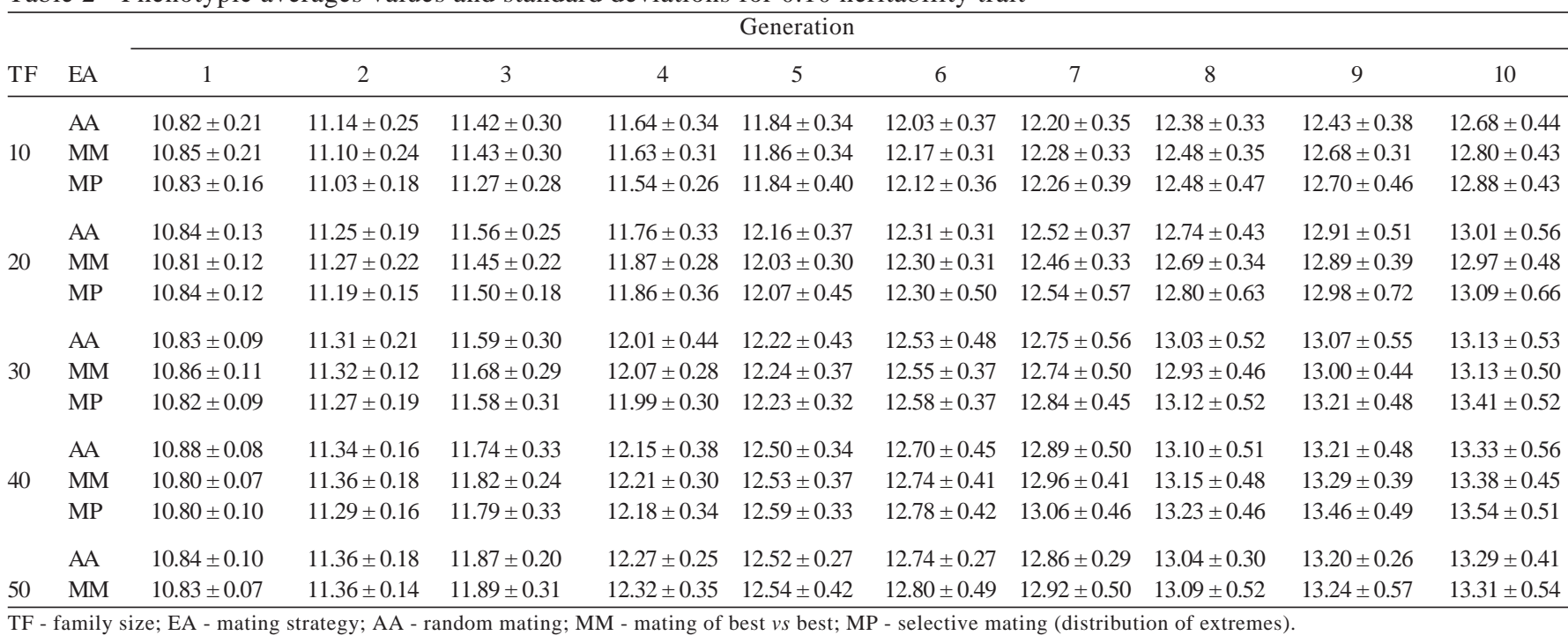


entire population. This percentage accounts for $81 \%$ of all information required to connect the marker and QTL (van Gestel et al., 2000). In contrast, those centered next to the mean phenotype of the population contribute little (Jin et al., 2004; Bueno Filho et al., 2006).

The selective mating provided lower endogamic average, favoring the maintenance of higher additive genetic variance over generations, in all admitted scenarios (Tables 3 and 4). Equivalence in endogamic averages and genetic variability was also observed between the other two strategies. The additive genetic variance in a population decreases as individuals become more inbred, favoring smaller gains over the generations (Breda et al., 2004; Cunha et al., 2004; Reis et al., 2009).
The selective mating slows consanguinity among individuals and maintains higher levels of genetic variability. Indirectly, this strategy optimizes the detection of QTL, in accordance with the superiority of the phenotypic increments obtained in the marker-assisted selection (Table 2).

In marker-assisted selection, the QTL analysis requires that molecular markers be in linkage disequilibrium with the segregating alleles at loci that influence quantitative and/or interest traits. Linkage disequilibrium is a nonrandom association between alleles at different loci in a population (Flint-Garcia et al., 2003). It is favored in matings involving individuals divergent in gene frequency related to the characteristic.

Table 3 - Endogamy average and standard deviations for 0.10 heritability trait

\begin{tabular}{|c|c|c|c|c|c|c|c|c|c|c|c|}
\hline \multirow[b]{2}{*}{$\mathrm{TF}$} & \multirow[b]{2}{*}{ EA } & \multicolumn{9}{|c|}{ Generation } & \multirow[b]{2}{*}{10} \\
\hline & & 1 & 2 & 3 & 4 & 5 & 6 & 7 & 8 & 9 & \\
\hline \multirow{3}{*}{10} & $\mathrm{AA}$ & $0.040 \pm 0.015$ & $0.168 \pm 0.093$ & $0.256 \pm 0.109$ & $0.304 \pm 0.118$ & $0.362 \pm 0.120$ & $0.415 \pm 0.114$ & $0.457 \pm 0.124$ & $0.479 \pm 0.111$ & $0.520 \pm 0.105$ & $0.558 \pm 0.100$ \\
\hline & MM & $0.042 \pm 0.019$ & $0.178 \pm 0.082$ & $0.269 \pm 0.102$ & $0.324 \pm 0.110$ & $0.375 \pm 0.114$ & $0.424 \pm 0.117$ & $0.477 \pm 0.103$ & $0.508 \pm 0.118$ & $0.549 \pm 0.114$ & $0.589 \pm 0.102$ \\
\hline & MP & $0.023 \pm 0.011$ & $0.093 \pm 0.053$ & $0.172 \pm 0.060$ & $0.245 \pm 0.086$ & $0.297 \pm 0.099$ & $0.331 \pm 0.089$ & $0.371 \pm 0.087$ & $0.423 \pm 0.083$ & $0.461 \pm 0.086$ & $0.517 \pm 0.081$ \\
\hline \multirow{3}{*}{20} & AA & $0.044 \pm 0.021$ & $0.247 \pm 0.096$ & $0.332 \pm 0.106$ & $0.379 \pm 0.098$ & $0.457 \pm 0.111$ & $0.514 \pm 0.107$ & $0.567 \pm 0.72$ & $0.612 \pm 0.071$ & $0.655 \pm 0.87$ & $0.693 \pm 0.071$ \\
\hline & MM & $0.050 \pm 0.023$ & $0.268 \pm 0.074$ & $0.342 \pm 0.086$ & $0.408 \pm 0.089$ & $0.450 \pm 0.104$ & $0.512 \pm 0.072$ & $0.544 \pm 0.082$ & $0.587 \pm 0.078$ & $0.622 \pm 0.071$ & $0.654 \pm 0.068$ \\
\hline & MP & $0.033 \pm 0.014$ & $0.120 \pm 0.066$ & $0.227 \pm 0.062$ & $0.288 \pm 0.096$ & $0.354 \pm 0.070$ & $0.417 \pm 0.077$ & $0.497 \pm 0.084$ & $0.551 \pm 0.079$ & $0.586 \pm 0.081$ & $0.611 \pm 0.073$ \\
\hline \multirow{3}{*}{30} & $\mathrm{AA}$ & $0.086 \pm 0.034$ & $0.259 \pm 0.074$ & $0.340 \pm 0.098$ & $0.433 \pm 0.093$ & $0.489 \pm 0.089$ & $0.559 \pm 0.097$ & $0.626 \pm 0.086$ & $0.676 \pm 0.075$ & $0.722 \pm 0.075$ & $0.755 \pm 0.076$ \\
\hline & MM & $0.091 \pm 0.030$ & $0.297 \pm 0.063$ & $0.357 \pm 0.091$ & $0.438 \pm 0.077$ & $0.515 \pm 0.076$ & $0.564 \pm 0.084$ & $0.638 \pm 0.084$ & $0.682 \pm 0.068$ & $0.720 \pm 0.072$ & $0.754 \pm 0.074$ \\
\hline & MP & $0.069 \pm 0.026$ & $0.158 \pm 0.059$ & $0.244 \pm 0.059$ & $0.313 \pm 0.072$ & $0.391 \pm 0.085$ & $0.457 \pm 0.077$ & $0.515 \pm 0.078$ & $0.571 \pm 0.065$ & $0.607 \pm 0.062$ & $0.649 \pm 0.061$ \\
\hline \multirow{3}{*}{40} & $\mathrm{AA}$ & $0.101 \pm 0.027$ & $0.297 \pm 0.058$ & $0.376 \pm 0.062$ & $0.442 \pm 0.076$ & $0.509 \pm 0.074$ & $0.549 \pm 0.078$ & $0.600 \pm 0.066$ & $0.650 \pm 0.050$ & $0.693 \pm 0.053$ & $0.728 \pm 0.049$ \\
\hline & MM & $0.099 \pm 0.034$ & $0.313 \pm 0.046$ & $0.400 \pm 0.059$ & $0.455 \pm 0.055$ & $0.533 \pm 0.063$ & $0.583 \pm 0.066$ & $0.627 \pm 0.067$ & $0.666 \pm 0.077$ & $0.712 \pm 0.063$ & $0.742 \pm 0.068$ \\
\hline & MP & $0.074 \pm 0.026$ & $0.168 \pm 0.092$ & $0.235 \pm 0.063$ & $0.322 \pm 0.100$ & $0.413 \pm 0.094$ & $0.478 \pm 0.089$ & $0.526 \pm 0.099$ & $0.593 \pm 0.094$ & $0.640 \pm 0.074$ & $0.695 \pm 0.068$ \\
\hline \multirow{3}{*}{50} & $\mathrm{AA}$ & $0.095 \pm 0.038$ & $0.298 \pm 0.057$ & $0.393 \pm 0.077$ & $0.473 \pm 0.090$ & $0.530 \pm 0.083$ & $0.607 \pm 0.090$ & $0.656 \pm 0.089$ & $0.715 \pm 0.091$ & $0.758 \pm 0.088$ & $0.795 \pm 0.084$ \\
\hline & MM & $0.096 \pm 0.036$ & $0.293 \pm 0.068$ & $0.386 \pm 0.060$ & $0.485 \pm 0.064$ & $0.541 \pm 0.060$ & $0.609 \pm 0.058$ & $0.675 \pm 0.062$ & $0.712 \pm 0.068$ & $0.762 \pm 0.060$ & $0.798 \pm 0.050$ \\
\hline & MP & $0.075 \pm 0.022$ & $0.195 \pm 0.044$ & $0.285 \pm 0.059$ & $0.395 \pm 0.079$ & $0.451 \pm 0.072$ & $0.518 \pm 0.066$ & $0.581 \pm 0.064$ & $0.632 \pm 0.058$ & $0.673 \pm 0.057$ & $0.718 \pm 0.060$ \\
\hline
\end{tabular}

Table 4 - Additive genetic variance and standard deviation for 0.10 heritability trait

\begin{tabular}{|c|c|c|c|c|c|c|c|c|c|c|c|}
\hline \multirow[b]{2}{*}{$\mathrm{TF}$} & \multirow[b]{2}{*}{ EA } & \multicolumn{9}{|c|}{ Generation } & \multirow[b]{2}{*}{10} \\
\hline & & 1 & 2 & 3 & 4 & 5 & 6 & 7 & 8 & 9 & \\
\hline \multirow{3}{*}{10} & $\mathrm{AA}$ & $0.33 \pm 0.05$ & $0.29 \pm 0.09$ & $0.27 \pm 0.09$ & $0.22 \pm 0.08$ & $0.19 \pm 0.07$ & $0.19 \pm 0.09$ & $0.18 \pm 0.07$ & $0.14 \pm 0.05$ & $0.13 \pm 0.05$ & $0.11 \pm 0.04$ \\
\hline & $\mathrm{MM}$ & $0.34 \pm 0.04$ & $0.29 \pm 0.10$ & $0.26 \pm 0.10$ & $0.24 \pm 0.09$ & $0.20 \pm 0.07$ & $0.17 \pm 0.06$ & $0.16 \pm 0.05$ & $0.14 \pm 0.06$ & $0.13 \pm 0.05$ & $0.12 \pm 0.06$ \\
\hline & MP & $0.38 \pm 0.04$ & $0.33 \pm 0.08$ & $0.32 \pm 0.09$ & $0.27 \pm 0.10$ & $0.24 \pm 0.09$ & $0.23 \pm 0.08$ & $0.20 \pm 0.08$ & $0.18 \pm 0.06$ & $0.16 \pm 0.06$ & $0.14 \pm 0.05$ \\
\hline \multirow{3}{*}{20} & AA & $0.32 \pm 0.04$ & $0.26 \pm 0.04$ & $0.23 \pm 0.06$ & $0.21 \pm 0.07$ & $0.17 \pm 0.05$ & $0.15 \pm 0.04$ & $0.11 \pm 0.03$ & $0.10 \pm 0.03$ & $0.09 \pm 0.04$ & $0.08 \pm 0.04$ \\
\hline & MM & $0.33 \pm 0.03$ & $0.25 \pm 0.04$ & $0.24 \pm 0.07$ & $0.17 \pm 0.05$ & $0.16 \pm 0.04$ & $0.15 \pm 0.05$ & $0.12 \pm 0.04$ & $0.10 \pm 0.03$ & $0.10 \pm 0.04$ & $0.09 \pm 0.04$ \\
\hline & MP & $0.34 \pm 0.04$ & $0.31 \pm 0.07$ & $0.27 \pm 0.06$ & $0.25 \pm 0.07$ & $0.21 \pm 0.08$ & $0.18 \pm 0.06$ & $0.15 \pm 0.06$ & $0.14 \pm 0.07$ & $0.12 \pm 0.04$ & $0.10 \pm 0.04$ \\
\hline \multirow{3}{*}{30} & AA & $0.34 \pm 0.03$ & $0.27 \pm 0.07$ & $0.22 \pm 0.06$ & $0.19 \pm 0.07$ & $0.15 \pm 0.06$ & $0.13 \pm 0.05$ & $0.10 \pm 0.03$ & $0.07 \pm 0.02$ & $0.06 \pm 0.03$ & $0.05 \pm 0.02$ \\
\hline & $\mathrm{MM}$ & $0.33 \pm 0.03$ & $0.25 \pm 0.04$ & $0.20 \pm 0.04$ & $0.18 \pm 0.06$ & $0.14 \pm 0.05$ & $0.11 \pm 0.03$ & $0.10 \pm 0.05$ & $0.08 \pm 0.04$ & $0.07 \pm 0.03$ & $0.05 \pm 0.02$ \\
\hline & MP & $0.34 \pm 0.02$ & $0.29 \pm 0.05$ & $0.25 \pm 0.07$ & $0.23 \pm 0.08$ & $0.19 \pm 0.06$ & $0.18 \pm 0.07$ & $0.13 \pm 0.06$ & $0.12 \pm 0.04$ & $0.10 \pm 0.04$ & $0.07 \pm 0.04$ \\
\hline \multirow{3}{*}{40} & AA & $0.33 \pm 0.03$ & $0.24 \pm 0.04$ & $0.19 \pm 0.04$ & $0.16 \pm 0.05$ & $0.13 \pm 0.03$ & $0.12 \pm 0.04$ & $0.09 \pm 0.03$ & $0.07 \pm 0.03$ & $0.06 \pm 0.03$ & $0.05 \pm 0.02$ \\
\hline & $\mathrm{MM}$ & $0.35 \pm 0.03$ & $0.27 \pm 0.04$ & $0.19 \pm 0.04$ & $0.15 \pm 0.03$ & $0.13 \pm 0.04$ & $0.11 \pm 0.04$ & $0.10 \pm 0.05$ & $0.07 \pm 0.02$ & $0.05 \pm 0.02$ & $0.05 \pm 0.02$ \\
\hline & MP & $0.33 \pm 0.03$ & $0.29 \pm 0.06$ & $0.25 \pm 0.04$ & $0.20 \pm 0.04$ & $0.17 \pm 0.05$ & $0.14 \pm 0.05$ & $0.12 \pm 0.04$ & $0.10 \pm 0.04$ & $0.09 \pm 0.03$ & $0.07 \pm 0.03$ \\
\hline \multirow{3}{*}{50} & AA & $0.33 \pm 0.02$ & $0.24 \pm 0.05$ & $0.18 \pm 0.04$ & $0.14 \pm 0.03$ & $0.13 \pm 0.05$ & $0.10 \pm 0.05$ & $0.08 \pm 0.04$ & $0.06 \pm 0.04$ & $0.05 \pm 0.03$ & $0.04 \pm 0.02$ \\
\hline & $\mathrm{MM}$ & $0.33 \pm 0.03$ & $0.26 \pm 0.06$ & $0.20 \pm 0.05$ & $0.15 \pm 0.04$ & $0.13 \pm 0.05$ & $0.09 \pm 0.03$ & $0.08 \pm 0.03$ & $0.05 \pm 0.03$ & $0.05 \pm 0.02$ & $0.04 \pm 0.02$ \\
\hline & MP & $0.34 \pm 0.02$ & $0.30 \pm 0.05$ & $0.24 \pm 0.05$ & $0.19 \pm 0.06$ & $0.15 \pm 0.05$ & $0.12 \pm 0.04$ & $0.11 \pm 0.04$ & $0.09 \pm 0.04$ & $0.07 \pm 0.02$ & $0.06 \pm 0.02$ \\
\hline
\end{tabular}

TF - family size; EA - mating strategy; AA - random mating; MM - mating of best $v s$ best; MP - selective mating (distribution of extremes). 
The mating that uses the distribution of extremes enhances the linkage disequilibrium, regardless of the magnitude of family size. In selective breeding, inbreeding levels are lower, while the genetic variability remains higher, in analogy to the other mating types. The benefit provided to the linkage disequilibrium enables the identification and detection of QTL associated with segregating genetic markers.

It is noteworthy that the selective strategy that uses the distribution of extremes can reduce the number of generations to achieve similar phenotypic increments, when compared with random and between the best matings. Equivalence in phenotypic value was obtained for the family with 30 descendents in the 8th generation when adopting the distribution of extremes with the resulting values only in the10th generation in admitting the other matings (Table 2). The inbreeding coefficient may also have delayed its magnitude within two generations, on average, especially in smaller families (Table 3). The additive genetic variance, by allowing the distribution of extremes, can have its value equated with those obtained from the two previous generations, although applying the other types of mating (Table 4).

Selective mating also enables better estimates when comparing different family sizes, which indicates a reduction in the number of individuals required in the population for mapping quantitative loci. Analogy between the phenotypic values of selective mating, assuming family size 30 and/or 40 , and the other two methods of breeding, considering size 50 , shows the superiority of the distribution of extremes in phenotypic increment (Table 2). This advantage also applies to the parameter estimates inbreeding and additive genetic variance. The distribution of the extremes gets equivalence in the delay of endogamy by allowing larger family sizes in comparison with the other two strategies, however, considering families of smaller sizes (Table 3), while the genetic variability presented better magnitudes for larger families which used the selective strategy in analogy with those of smaller sizes that did not adopt selective mating (Table 4). These results corroborated the reduction in the number of individuals required in the analysis of quantitative loci for a given capacity of QTL detection, as reported by Darvasi \& Soller (1992), Jannink (2005) and Ruy et al. (2005).

Subjecting an initial population with the same genomic structure to the mating strategies under marker-assisted selection, but considering a quantitative characteristic of medium heritability $\left(h^{2}=0.40\right)$, the mean of the phenotypic value, endogamy and additive genetic variance parameters were estimated (Tables 5, 6 and 7).

The phenotypic values once again show the effectiveness of selective mating on the other strategies, when facing higher increments, from intermediate generations (Table 5). Further phenotypic progresses were obtained with a smaller number of generations under markerassisted selection (Table 5). The phenotypic average gain was superior in comparison to the previous trait $\left(\mathrm{h}^{2}=0.10\right)$, for considering a character with higher heritability.

The differences between the systems of mating, according to family size, were kept to the endogamic averages (Table 6). The primary consequence of inbreeding is the phenomenon known as endogamic depression, characterized by reduction in average phenotype (Queiroz et al., 2000; Silva etal., 2001; Cunha et al., 2004). The endogamy coefficients of smaller magnitude are related to higher phenotypic values, according to family size and type of mating (Tables 5 and 6 ).

Table 5 - Average phenotypic values and standard deviations for 0.40 heritability trait Generation

\begin{tabular}{llcccccccccc} 
TF & EA & 1 & 2 & 3 & 4 & 5 & 6 & 7 & 8 & 9 \\
\hline & AA & $11.67 \pm 0.19$ & $12.33 \pm 0.26$ & $12.76 \pm 0.32$ & $13.38 \pm 0.39$ & $14.00 \pm 0.46$ & $14.53 \pm 0.61$ & $15.12 \pm 0.65$ & $15.70 \pm 0.79$ & $16.16 \pm 0.79$ & $16.58 \pm 0.86$ \\
10 & MM & $11.68 \pm 0.19$ & $12.24 \pm 0.29$ & $12.80 \pm 0.34$ & $13.46 \pm 0.37$ & $14.12 \pm 0.47$ & $14.73 \pm 0.42$ & $15.25 \pm 0.40$ & $15.87 \pm 0.48$ & $16.35 \pm 0.51$ & $16.87 \pm 0.65$ \\
& MP & $11.62 \pm 0.23$ & $12.59 \pm 0.31$ & $13.33 \pm 0.43$ & $13.98 \pm 0.58$ & $14.65 \pm 0.59$ & $15.23 \pm 0.64$ & $15.97 \pm 0.61$ & $16.49 \pm 0.72$ & $16.89 \pm 0.69$ & $17.26 \pm 0.65$ \\
& AA & $11.72 \pm 0.13$ & $12.29 \pm 0.33$ & $13.15 \pm 0.28$ & $14.0 \pm 0.44$ & $14.69 \pm 0.52$ & $15.40 \pm 0.61$ & $16.11 \pm 0.70$ & $16.62 \pm 0.70$ & $17.07 \pm 0.69$ & $17.37 \pm 0.82$ \\
20 & MM & $11.70 \pm 0.16$ & $12.39 \pm 0.26$ & $13.21 \pm 0.31$ & $13.97 \pm 0.28$ & $14.57 \pm 0.51$ & $15.28 \pm 0.67$ & $16.03 \pm 0.63$ & $16.47 \pm 0.66$ & $17.04 \pm 0.73$ & $17.41 \pm 0.81$ \\
& MP & $11.68 \pm 0.16$ & $12.88 \pm 0.24$ & $13.85 \pm 0.34$ & $14.73 \pm 0.45$ & $15.59 \pm 0.47$ & $16.24 \pm 0.61$ & $16.94 \pm 0.70$ & $17.42 \pm 0.82$ & $17.94 \pm 0.86$ & $18.31 \pm 1.00$ \\
& AA & $11.64 \pm 0.10$ & $12.28 \pm 0.23$ & $13.19 \pm 0.36$ & $14.10 \pm 0.46$ & $14.82 \pm 0.44$ & $15.43 \pm 0.43$ & $16.04 \pm 0.53$ & $16.69 \pm 0.56$ & $17.10 \pm 0.67$ & $17.33 \pm 0.81$ \\
30 & MM & $11.65 \pm 0.11$ & $12.36 \pm 0.21$ & $13.21 \pm 0.38$ & $14.30 \pm 0.38$ & $15.09 \pm 0.51$ & $15.77 \pm 0.55$ & $16.48 \pm 0.57$ & $17.06 \pm 0.55$ & $17.44 \pm 0.75$ & $17.72 \pm 0.84$ \\
& MP & $11.65 \pm 0.10$ & $12.89 \pm 0.34$ & $14.19 \pm 0.45$ & $15.15 \pm 0.41$ & $15.98 \pm 0.52$ & $16.70 \pm 0.49$ & $17.32 \pm 0.60$ & $17.86 \pm 0.61$ & $18.27 \pm 0.56$ & $18.69 \pm 0.58$ \\
& AA & $11.66 \pm 0.09$ & $12.31 \pm 0.24$ & $13.36 \pm 0.43$ & $14.18 \pm 0.52$ & $14.89 \pm 0.66$ & $15.58 \pm 0.77$ & $16.07 \pm 0.79$ & $16.58 \pm 0.89$ & $17.04 \pm 0.92$ & $17.29 \pm 0.90$ \\
40 & MM & $11.66 \pm 0.14$ & $12.41 \pm 0.19$ & $13.50 \pm 0.46$ & $14.45 \pm 0.60$ & $15.32 \pm 0.65$ & $16.02 \pm 0.69$ & $16.62 \pm 0.66$ & $17.03 \pm 0.76$ & $17.46 \pm 0.82$ & $17.82 \pm 0.93$ \\
& MP & $11.65 \pm 0.10$ & $12.87 \pm 0.41$ & $14.21 \pm 0.60$ & $15.12 \pm 0.67$ & $16.12 \pm 0.76$ & $16.86 \pm 0.74$ & $17.44 \pm 0.68$ & $17.97 \pm 0.69$ & $18.42 \pm 0.85$ & $18.75 \pm 0.84$ \\
& AA & $11.65 \pm 0.08$ & $12.43 \pm 0.16$ & $13.56 \pm 0.32$ & $14.49 \pm 0.43$ & $15.27 \pm 0.46$ & $16.04 \pm 0.48$ & $16.58 \pm 0.66$ & $17.11 \pm 0.66$ & $17.49 \pm 0.82$ & $17.88 \pm 0.96$ \\
50 & MM & $11.63 \pm 0.08$ & $12.35 \pm 0.25$ & $13.49 \pm 0.53$ & $14.45 \pm 0.69$ & $15.31 \pm 0.80$ & $16.03 \pm 0.95$ & $16.62 \pm 1.15$ & $17.07 \pm 1.26$ & $17.46 \pm 1.36$ & $17.84 \pm 1.38$ \\
& MP & $11.66 \pm 0.07$ & $12.94 \pm 0.22$ & $14.15 \pm 0.50$ & $15.12 \pm 0.70$ & $15.96 \pm 0.73$ & $16.72 \pm 0.66$ & $17.32 \pm 0.77$ & $17.87 \pm 0.75$ & $18.19 \pm 0.85$ & $18.44 \pm 0.92$ \\
\hline
\end{tabular}

TF - family size; EA - mating strategy; AA - random mating; MM - mating of best vs best; MP - selective mating (distribution of extremes). 
Table 6 - Endogamy average and standard deviations for 0.40 heritability trait

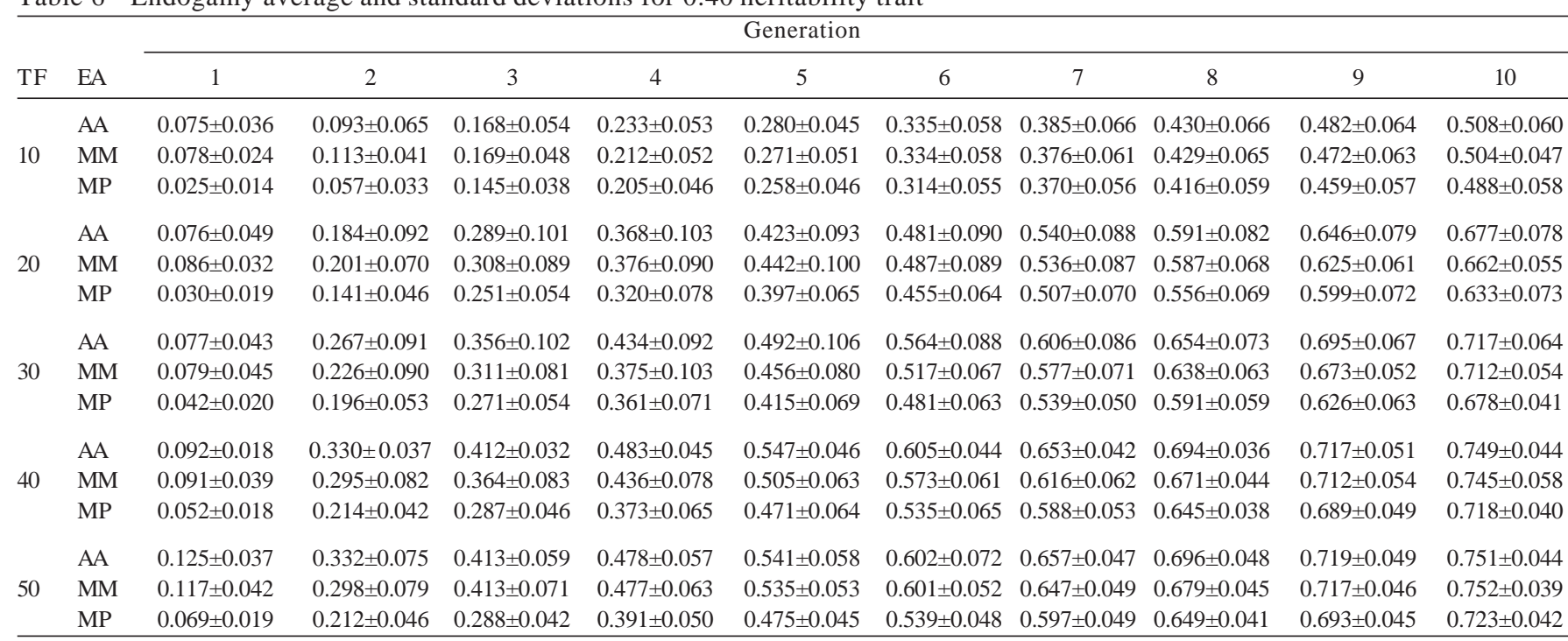

TF - family size; EA - mating strategy; AA - random mating; MM - mating of best vs best; MP - selective mating (distribution of extremes).

Table 7 - Additive genetic variance and standard deviation for 0.40 heritability trait

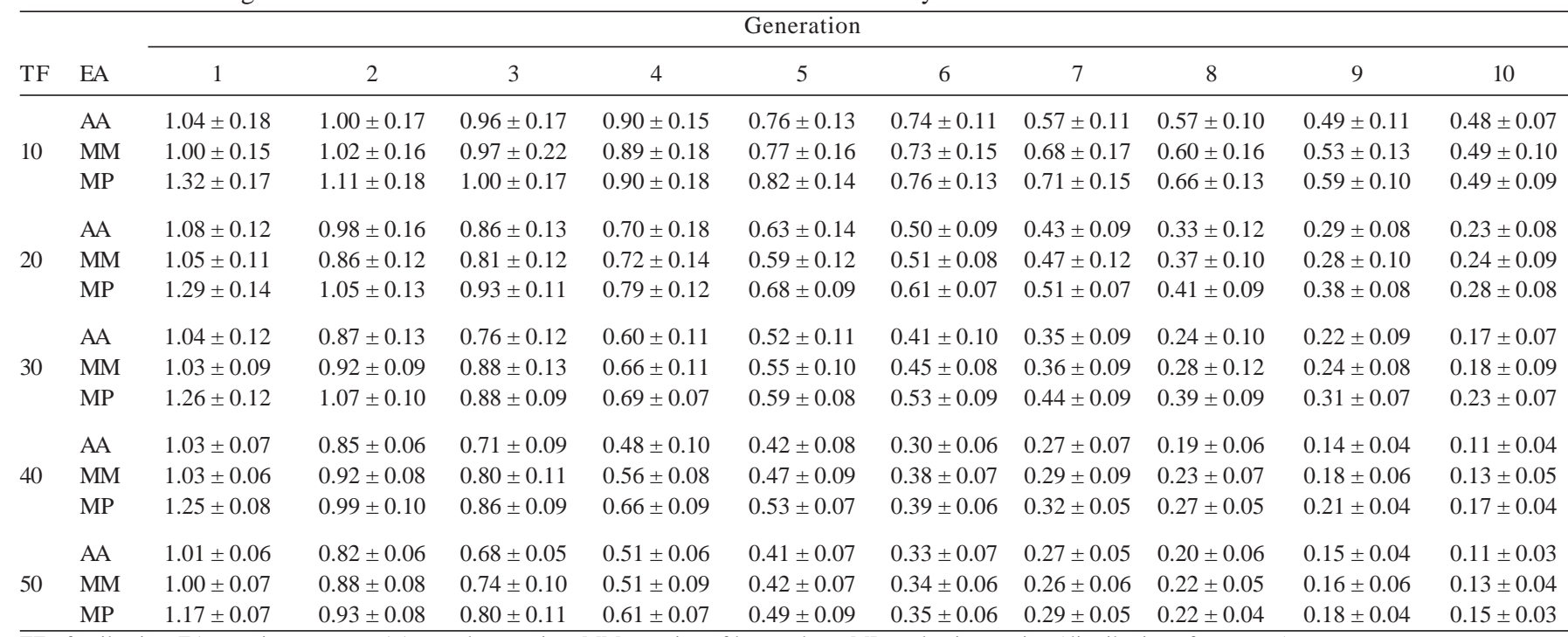

TF - family size; EA - mating strategy; AA - random mating; MM - mating of best vs best; MP - selective mating (distribution of extremes).

Estimates of additive genetic variance corroborated to show the superiority of the distribution of extremes compared with the other strategies (Table 7). The selective mating maintained the ability to delay the inbreeding coefficient in at least a generation, as well as maintaining a similar magnitude of genetic variability when considering an extra generation in marker-assisted selection. The other results followed the patterns reported for the trait of low heritability, with supremacy of selective mating.

The combination of mating strategies with the use of molecular markers, in breeding programs implemented through marker-assisted selection, can help slow the increase in endogamy and promote genetic variability (Lee
\& van der Werf, 2004). The search for new experimental methodologies that aim to slow the endogamic impacts will allow better use of available genetic variability in the population under selection, confirming the genetic improvement programs.

\section{Conclusions}

It is acceptable that the distribution of extremes favors the genetic variability. Selective mating slows the increase in the endogamy coefficient. This mating strategy benefits the phenotypic increment and, indirectly, enables the detection of quantitative trait loci in marker-assisted selection. 


\section{Acknowledgements}

To Universidade Federal de Viçosa (UFV) and Carlos Fundação de Amparo à Pesquisa do Estado do Rio de Janeiro (FAPERJ), for financial support.

\section{References}

BHERING, L.L.; CRUZ, C.D. Tamanho de população ideal para mapeamento genético em famílias de irmãos completos. Pesquisa Agropecuária Brasileira, v.43, n.3, p.379-385, 2008.

BOVENHUIS, H.; SPELMAN, R.J. Selective genotyping to detect quantitative trait loci for multiple traits in outbred populations. Journal of Dairy Science, v.83, n.1, p.173-180, 2000.

BREDA, F.C.; EUCLYDES, R.F.; PEREIRA, C.S. et al. Endogamia e limite de seleção em populações selecionadas obtidas por simulação. Revista Brasileira de Zootecnia, v.33, n.6, p.2017-2025, 2004.

BUENO FILHO, J.S.D.; GILMOUR, S.G.; ROSA, G.J.M. Design of microarray experiments for genetical genomics studies. Genetics, v.74, n.2, p.945-957, 2006.

CARNEIRO, P.L.S.; MACHADO, C.H.M.; EUCLYDES, R.F. et al. Endogamia, fixação de alelos e limite de seleção em populações selecionadas por métodos tradicionais e associados a marcadores moleculares. Revista Brasileira de Zootecnia, v.36, n.2, p.369-375, 2007.

CUNHA, E.E.; EUCLYDES, R.F.; TORRES, R.A. et al. Variabilidade genética e limite da seleção em populações de diferentes tipos de acasalamento. Arquivo Brasileiro de Medicina Veterinária e Zootecnia, v.56, n.2, p.242-250, 2004.

DARVASI, A.; SOLLER, M. Selective genotyping for determination of linkage between a marker locus and a quantitative trait locus. Theoretical and Applied Genetics, v.85, n.2-3, p.353-359, 1992.

EUCLYDES, R.F. Genesys: Sistema de simulação genética. Viçosa, MG: Fundação Arthur Bernardes - UFV, 2009. (CD-ROM).

FLINT-GARCIA, S.A.; THORNSBERRY, J.M.; BUCKLER, E.S. Structure of linkage disequilibrium in plants. Annual Review of Plant Biology, v.54, p.357-374, 2003.

JACOMETO, C.B.; BARRERO, N.M.L.; RODRIGUEZ-RODRIGUEZ, M.D.P. et al. Variabilidade genética em tambaquis (Teleostei: Characidae) de diferentes regiões do Brasil. Pesquisa Agropecuária Brasileira, v.45, p.481-487, 2010.

JANNINK, J.L. Selective phenotyping to accurately map quantitative trait loci. Crop Science, v.45, n.3, p.901-908, 2005.

JIN, C.; LAN, H.; ATTIE, A.D. et al. Selective phenotyping for increased efficiency in genetic mapping studies. Genetics, v.168, n.4, p.2285-2293, 2004.
LEE, S.H.; VAN DER WERF, J.H.J. The efficiency of designs for fine-mapping of quantitative trait loci using combined linkage disequilibrium and linkage. Genetics Selection Evolution, v.36, n.2, p.145-161, 2004.

MALHADO, C.H.M.; CARNEIRO, P.L.S.; MARTINS FILHO, R. et al. Histórico genético e populacional do rebanho Nelore Puro de Origem no Sertão Nordestino. Pesquisa Agropecuária Brasileira, v.44, n.7, p.713-718, 2009.

MOREIRA, A.A.; HILSDORF, A.W.S.; SILVA, J.V. et al. Variabilidade genética de duas variedades de tilápia nilótica por meio de marcadores microssatélites. Pesquisa Agropecuária Brasileira, v.42, n.4, p.521-526, 2007.

NEVES, H.H.R.; CAVALHEIRO, R.; CARDOSO, V. et al. Acasalamento dirigido para aumentar a produção de animais geneticamente superiores e reduzir a variabilidade da progênie em bovinos. Revista Brasileira de Zootecnia, v.38, n.7, p.1201-1204, 2009.

QUEIROZ, S.A.; ALBUQUERQUE, L.G.; LANZONI, N.A. Efeito da endogamia sobre características de crescimento de bovinos da raça Gir no Brasil. Revista Brasileira de Zootecnia, v.29, n.4, p.1014-1019, 2000.

REIS, R.L.; MUNIZ, J.A.; SILVA, F.F. et al. Estimativas de variância genética aditiva em populações selecionadas e nãoselecionadas via simulação monte carlo utilizando o software R. Ciência e Agrotecnologia, v.33, n.1, p.285-291, 2009.

RODRIGUES, J.I.S.; MIRANDA, F.D.; FERREIRA, A. et al. Mapeamento de QTL para conteúdos de proteína e óleo em soja. Pesquisa Agropecuária Brasileira, v.45, n.5, p.472-480, 2010.

ROSA, G.J.M. Delineamento de experimentos em genética genômica. Revista Brasileira de Zootecnia, v.36, p.211-218, 2007 (supl.).

RUY, D.C.; NONES, K.; BARON, E.E. et al. Strategic marker selection to detect quantitative trait loci in chicken. Scientia Agricola, v.62, n.2, p.111-116, 2005.

SCHUSTER, I.; CRUZ, C.D. Estatística genômica aplicada a populações derivadas de cruzamentos controlados. 2.ed. Viçosa, MG: Editora UFV, 2008. 568p.

SILVA, M.V.G.B.; FERREIRA, W.J.; COBUCI, J.A. et al. Efeito da endogamia sobre características produtivas e reprodutivas de bovinos do Ecótipo Mantiqueira. Revista Brasileira de Zootecnia, v.30, n.4, p.1236-1242, 2001.

SOUSA, K.R.S.; GUIMARÃES, S.E.F.; SILVA FILHO, M.I. et al. Mapeamento de locus de características quantitativas nos cromossomos 5, 7 e 8 de suínos. Revista Brasileira de Zootecnia, v.40, n.1, p.115-123, 2011.

VAN GESTEL, S.; HOUWING-DUISTERMAAT, J.J.; ADOLFSSON, R. et al. Power of selective genotyping in genetic association analyses of quantitative traits. Behavior Genetics, v.30, n.2, p.141-146, 2000. 